\title{
Wave Engine Topping Cycle Assessment
}

Gerard E. Welch

U.S. Army Research Laboratory

Lewis Research Center

Cleveland, Ohio

Prepared for the

35th Aerospace Sciences Meeting \& Exhibit

sponsored by the American Institute of Aeronautics and Astronautics

Reno, Nevada, January 6-10, 1997

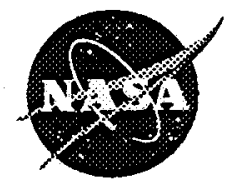

National Aeronautics and

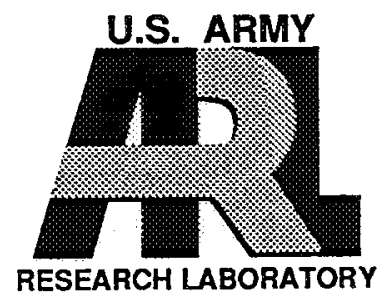




\title{
Wave Engine Topping Cycle Assessment
}

\author{
Gerard E. Welch* \\ Army Research Laboratory \\ NASA Lewis Research Center \\ 21000 Brookpark Road, M/S 77-6 \\ Cleveland, $\mathrm{OH} 44135$
}

\begin{abstract}
The performance benefits derived by topping a gas turbine engine with a wave engine are assessed. The wave engine is a wave rotor that produces shaft power by exploiting gas dynamic energy exchange and flow turning. The wave engine is added to the baseline turboshaft engine while keeping high-pressure-turbine inlet conditions, compressor pressure ratio, engine mass flow rate, and cooling flow fractions fixed. Related work has focused on topping with pressure-exchangers (i.e., wave rotors that provide pressure gain with zero net shaft power output); however, more energy can be added to a wave-engine-topped cycle leading to greater engine specific-power-enhancement. The energy addition occurs at a lower pressure in the wave-engine-topped cycle; thus the specific-fuel-consumption-enhancement effected by ideal wave engine topping is slightly lower than that effected by ideal pressure-exchanger topping. At a component level, however, flow turning affords the wave engine a degree-of-freedom relative to the pressure-exchanger that enables a more efficient match with the baseline engine. In some cases, therefore, the SFC-enhancement by wave engine topping is greater than that by pressure-exchanger topping. An ideal wave-rotor-characteristic is used to identify key wave engine design parameters and to contrast the wave engine and pressure-exchanger topping approaches. An aerodynamic design procedure is described in which wave engine design-point performance levels are computed using a one-dimensional wave rotor model. Wave engines using various wave cycles are considered including two-port cycles with on-rotor combustion (valved-combustors) and reverse-flow and through-flow four-port cycles with heat addition in conventional burners. A through-flow wave cycle design with symmetric blading is used to assess engine performance benefits. The wave-engine-topped turboshaft engine produces $16 \%$ more power than does a pressureexchanger-topped engine under the specified topping constraints. Positive and negative aspects of wave engine topping in gas turbine engines are identified.
\end{abstract}

\section{Nomenclature}

$\mathrm{CPR}=$ compressor pressure ratio

$c \quad=0.0622$, windage loss model constant

$c_{R}^{\mathfrak{r}}=$ conversion factor $(2545.6 \mathrm{Btu} / \mathrm{hp}-\mathrm{hr})$

$f_{b}=\left(\dot{m}_{-}-\dot{m}\right) / \dot{m}_{i}$, coolant bleed fraction

$f_{W} \quad=L_{W}{ }^{i \eta} L_{P}$, local blade blockage fraction

$H R$. = ratio of inlet and outlet port absolute total enthalpies

$H R^{\prime} \quad=$ ratio of inlet and outlet port relative total enthalpies

$\tilde{h} \quad=$ specific total enthalpy

$\tilde{h}^{\prime} \quad=\tilde{h}-u_{\theta} r \Omega$, specific rothalpy

$\tilde{h}_{r} \quad=\tilde{h}-\frac{1}{2}(\underline{u} \cdot \underline{u}-\underline{w} \cdot \underline{w})$

$L_{P} \quad=$ rotor blade-to-blade distance at the tip

$L_{T} \quad=$ rotor chord length

$L_{w} \quad=$ blade-tip thickness at rotor ends

$\tilde{M}_{\mathrm{Q}, \text { in }}=\left(\left(R_{T} \Omega\right)^{2} /(\gamma-1) \tilde{h}_{i n}\right)^{1 / 2}$, rotor Mach number

$m^{\mathrm{Q}, \text { in }}=\operatorname{mass}$

$\dot{m} \quad=$ mass flow rate time-averaged over one wave cycle

$n \quad=$ number of wave rotor cycles per revolution

$n_{B} \quad=$ rotor blade count

$P R=\quad=\underset{p}{\tilde{p}} / \bar{p}_{\text {in }}$, wave rotor ratio of mixed-out total

$P R^{m} \quad=\tilde{p}_{e x}^{m} / \tilde{p}_{\text {in }}$, wave rotor ratio of mass-averaged total pressures

$p \quad=$ static pressure

$\tilde{p} \quad=$ total pressure

$Q \quad=$ rate of energy addition to wave rotor by combustion or heat transfer

$Q_{R} \quad=$ fuel heating value $\left(18,600 \mathrm{Btu} / \mathrm{lb}_{\mathrm{m}}\right)$

$R_{H} \quad=$ hub radius

$R_{T} \quad=$ rotor blade tip (or shroud inner-) radius

$R_{O}=R_{T}\left(1+0.05\left(1-R_{H} / R_{T}\right)\right)$, rotor-shroud outer-

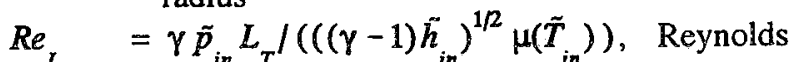
number based on inlet total ${ }^{\text {in }}$ conditions and rotor chord length.

$r \quad=$ radius

$\underline{r} \quad=(r, \theta, x)$, position vector 


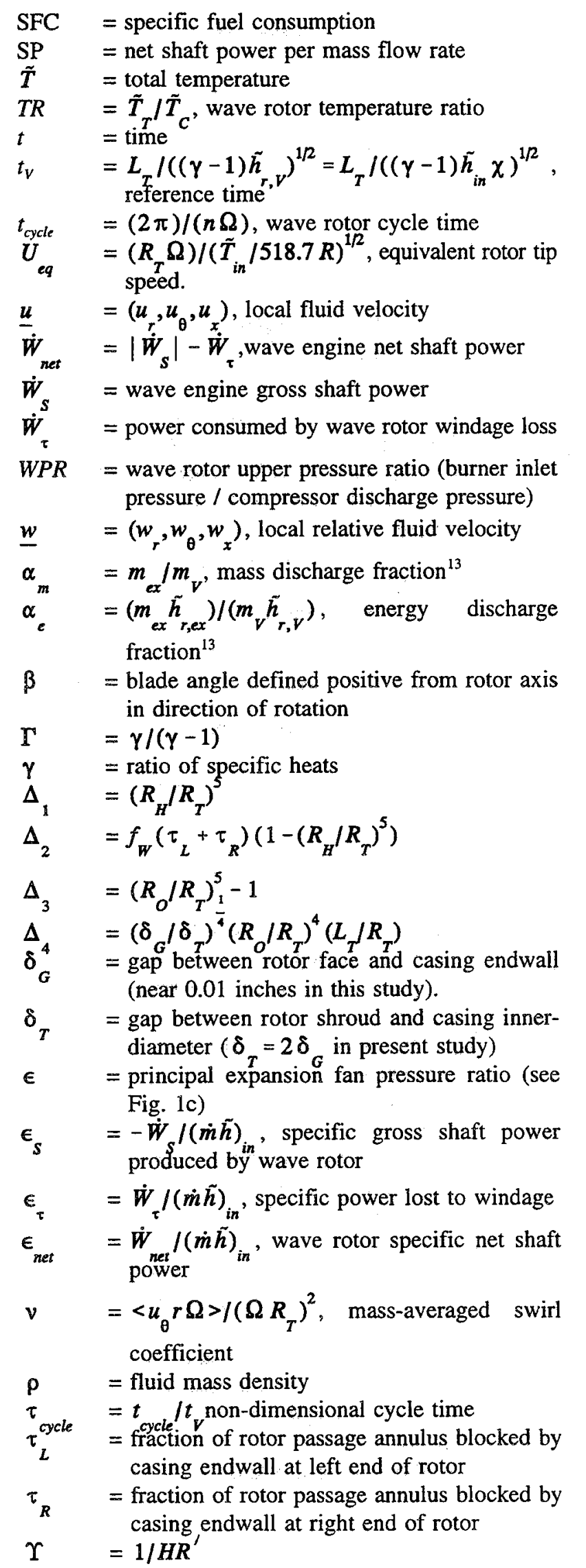

$$
\begin{array}{ll}
\chi & =\left(\alpha_{m} / \alpha_{e}\right)\left(H R-\frac{\gamma-1}{2} \tilde{M}_{Q, i n}^{2}\left(2 \nu_{e x}-1\right)\right) \\
\Omega & =\text { shaft angular speed } \\
<> & =\text { denotes mass-averaged quantity. }
\end{array}
$$

Subscripts:

$\begin{array}{ll}\mathrm{BASE} & =\text { baseline engine } \\ \mathrm{C} & =\text { compressor discharge } \\ \mathrm{ex} & =\text { wave rotor exit port } \\ \text { in } & =\text { wave rotor inlet port } \\ \mathrm{L} & =\text { left end of rotor } \\ \mathrm{PE} & =\text { pressure-exchanger } \\ \mathrm{R} & =\text { right end of rotor } \\ \mathrm{T} & =\text { turbine inlet } \\ \mathrm{V} & =\text { rotor passage content relative conditions just } \\ & \text { prior to low pressure exhaust port discharge } \\ \mathrm{WE} & =\text { wave engine. }\end{array}$

\section{Introduction}

The wave engine is a wave rotor designed to produce shaft power. It merges the gas dynamic energy exchange of wave rotor technology with the flow tuming of classical turbomachinery. Consider the energy equation for an inviscid flow written in a coordinate system fixed to a rotor spinning at constant angular speed,

$$
\rho \frac{D \tilde{h}}{D t^{\prime}}=\frac{\partial p}{\partial t^{\prime}}-\Omega \frac{\partial p}{\partial \theta^{\prime}},
$$

where the prime denotes the relative frame. In classical turbomachines $\partial p / \partial t^{\prime} \propto 0$; that is, neglecting strong inter-blade-row interactions, the flow is essentially "steady" in the rotor frame of reference and work is accomplished by flow turning (i.e., $\left.-\Omega \partial p / \partial \theta^{\prime}=\rho D\left(r \Omega u_{\theta}\right) / D t^{\prime}\right)$. By contrast, the flow in wave rotor passages is "unsteady" in the rotor frame of reference; that is, the work of the gas dynamic waves, $\partial p / \partial t^{\prime}$, is always significant in wave rotors. In axiallybladed pressure-exchangers, the flow turning is zero by design $\left(\partial p / \partial \theta^{\prime} \propto 0\right)$. In contrast, the wave engine rotor blades are designed (e.g., with stagger and camber) to change the angular momentum of the flow; hence, both $\partial p / \partial t^{\prime}$ and $\Omega \partial p / \partial \theta^{\prime}$ are significant work modes in the wave engine.

Like other wave rotors, the wave engine is a partial admission and partial emission device. It consists of a shrouded rotor which is surrounded by a stationary casing (see Fig. 1). The casing endwalls are penetrated by inlet and outlet ducts which port gas to and from the rotor passages. At any instant in time, portions of the rotor flow annuli are exposed to the ducts while the remaining portions face the casing endwalls. The gas dynamic waves are initiated as the rotor passages open and close to the ducted (nearly) steady-state flows of 
differing energy density (pressures and temperatures). Like other wave rotors, the wave engine can be partially or fully self-cooling: the walls (hub, shroud, and blade surfaces) of self-cooled portions of the rotor are alternately exposed to cold and hot gases at frequencies much higher than the thermal response frequency dictated by the rotor material and geometry. The rotor temperatures remain 20 to $25 \%$ lower than the peak gas temperature. This self-cooling feature enables waverotor-topped gas turbine engines to operate with peak cycle temperatures higher (e.g., 500 to $800 \mathrm{R}$ ) than currently attainable with classical turbomachinery, given current cooling technology and material temperature limits.

Pearson designed, built, and successfully tested a wave engine in the mid-fifties ${ }^{1}$ and compared the pressure-exchanger and wave engine topping approaches. ${ }^{2}$ Klapproth investigated the benefits of topping gas turbine engines with "turbowave" engines in the early sixties. ${ }^{3.4} \mathrm{~A}$ wave engine design has been documented by Coleman ${ }^{5}$ and Weber. ${ }^{6.7}$ Recently, Lear and $\mathrm{Kielb}^{8}$ used a thermodynamic description of wave rotors to show the significant potential benefits of wave engine topping in gas turbine engines and presented a preliminary design method for selecting the wave engine inflow and outflow blade angles.

The benefits of wave engine topping in a small (576 hp) turboshaft gas turbine engine are assessed in this paper. Ideal thermodynamic cycle descriptions are first used to compare the performance benefits offered by the pressure-exchanger and wave engine topping approaches, and thus motivate the study. An ideal wave rotor characteristic for a class of wave rotors is used to identify key wave engine design parameters. A onedimensional wave rotor model is used to aerodynamically design and predict the performance of wave engines operating with various wave cycles and heat addition approaches. The engine specific powerand SFC-enhancement effected by the wave engine topping is assessed and negative and positive aspects of the wave engine approach to wave rotor enhancement of gas turbine engines are discussed.

\section{Thermodynamic Analysis}

The benefits of wave rotor topping in gas turbine engines have been assessed in recent work ${ }^{9-11}$ in which a pressure-exchanger is added to a baseline engine while keeping the high pressure turbine (HPT) inlet temperature $\left(\tilde{T}_{)}\right)$and the compressor pressure ratio (CPR) fixed. This approach is adopted for the present wave engine assessment as well. Temperature-entropy diagrams for the baseline, pressure-exchanger-topped, and wave-engine-topped engines are provided in Fig. 2. Note that wave rotor topping can be applied in other ways; for example, rather than fixing CPR, it can be reoptimized to maximize an identified figure-of-merit (e.g., shaft power) as in the recent work of Lear and Kielb. ${ }^{8}$

Pressure-exchanger. The net shaft power of the pressure-exchanger (PE) is zero by design. Provided that the wave rotor is efficient and well designed the total pressure at the high pressure turbine (HPT) inlet is higher than the compressor discharge; that is, the wave rotor pressure ratio $\left(P R \equiv \tilde{p}_{e x} / \tilde{p}_{\text {in }}\right)$ will be greater than unity. The HPT turbine (gas generator) inlet temperature remains at $\tilde{T}_{T}$ and it still produces only the power to drive the compressor with the same CPR as the baseline engine; that is, the HPT expands from and to the same temperatures as in the baseline engine. The new low pressure turbine (LPT, or power turbine) extracts more power than the baseline LPT because of the higher overall turbine expansion ratio (ideally $\mathrm{CPR} * \mathrm{PR}$ ) afforded by the pressure gain. The heat added to the PE-topped cycle is the same as that added in the baseline cycle.

Wave Engine. The HPT inlet temperature and pressure of the wave-engine (WE)-topped engine are required to be identical to those of the baseline engine in this study. This is in contrast to the pressureexchanger approach: here $\mathrm{PR}$ is specified; in the pressure-exchanger approach, $\mathrm{PR}$ is maximized. At a given temperature ratio ( $T R \equiv \tilde{T}_{T} / \tilde{T}_{C}$ ), the wave engine "upper" compression ratio (WPR) is less than that of the pressure-exchanger due to the work extraction as indicated in Fig. 2. The amount of net shaft power extracted depends on the temperature ratio, the efficiency of the machine, and the specified pressure ratio, $P R$ (set by the baseline engine combustor pressure drop). In the wave engine approach, as in the baseline engine, the HPC supplies HPT cooling, in contrast to the pressure-exchanger (pressure-gain) topping approach in which HPT cooling air must be extracted from the wave rotor topping loop (cf. Refs. 9 and 10). The heat added to the WE-enhanced cycle is equal to that added in the baseline cycle (or in the PE-topped cycle) plus the wave engine net shaft power, $\dot{W}$; therefore, more power is ideally produced by the WE-topped engine than by the PE-topped engine.

Comparative ideal benefits. Consider ideal (i.e., $100 \%$ component efficiencies and zero burner pressure drops) baseline, PE-topped, and WE-topped Brayton cycles. The ratios of total shaft power and of specific fuel consumption of the two cycles are given by

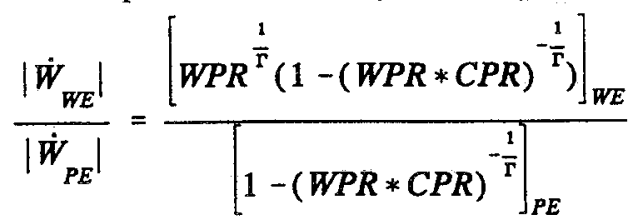


and

$$
\frac{S F C_{W E}}{S F C_{P E}}=\frac{\left[1-(W P R * C P R)^{-\frac{1}{r}}\right]_{P E}}{\left[1-(W P R * C P R)^{-\frac{1}{r}}\right]_{W E}},
$$

respectively, where $\Gamma \equiv \gamma / \gamma-1$, WPR is the wave rotor upper pressure ratio and CPR is the compressor pressure ratio. Figure 3 provides WPR and PR as a function of specific shaft power extraction $\left(\epsilon_{s}\right)$ in the reverse-flow, four-port wave rotor discussed in detail later. As shown, $W P R_{W E}<W P R_{P E}$ due to the work extraction in the wave engine. A typical pressure-exchanger upper pressure ratio for an example $T R=2.213$ and ratio of specific heats of 1.315 is $\mathrm{WPR}_{\mathrm{PE}}=2.50$ (at $\epsilon=0$ ). A corresponding wave engine with specified $T R=2.213$ and $P R=0.96$ corresponds to $\epsilon_{s}=0.125$ at which point $\mathrm{WPR}_{\mathrm{WE}}=2.2$. If the baseline engine has a $\mathrm{CPR}=7.77$, then the ratio of specific powers (Eqn. 2) above is 1.17 and the ratio of SFCs (Eqn. 3) is 1.03. The WE-topped cycle ideally provides $17 \%$ more power than the PEtopped cycle (which by similar analysis ideally provides about $31 \%$ more power than the baseline engine) while the WE-topped SFC is $3 \%$ higher than the PE-topped SFC (which by similar analysis is ideally about $24 \%$ lower than the baseline engine SFC). This combination of specific-power- and SFC-enhancement ideally effected by wave engine topping motivates the present work.

\section{Wave Engine Model}

A wave rotor model based on macroscopic balances was previously developed. ${ }^{12,13}$ The wave processes that effect energy transfer within the wave rotor passages are modeled as one-dimensional shock and expansion waves that run normal to the blade surfaces. Macroscopic mass and energy balances relate volume-averaged thermodynamic properties in the rotor passage control volume to the mass, momentum, and energy fluxes at the ports. Loss models account for entropy production in the boundary layers and in separating flows caused by blade-blockage, incidence, and gradual opening and closing of rotor passages. The model was extended in the present work to compute the power produced by flow turning and to account for the parasitic loss of shaft power to windage. Leakage, heat transfer, and flow-turning-induced secondary flow losses are neglected in the present study.

\section{Energy balances}

The specific gross shaft power produced by the wave rotor, $\epsilon_{s} \equiv-\dot{W}_{s} /(\dot{m}<\tilde{h}>)_{\text {in }}$, is given by

$$
\epsilon_{s}=\sum_{i} \frac{(\dot{m}<\tilde{h}>)_{i}}{(\dot{m}<\tilde{h}>)_{i n}}-\sum_{e} \frac{(\dot{m}<\tilde{h}>)_{e}}{(\dot{m}<\tilde{h}>)_{i n}}+\frac{Q}{(\dot{m}<\tilde{h}>)_{i n}}
$$

for $\mathrm{i}$ inlet ports and e outlet ports, where "in" represents a reference inlet port (the port from the compressor is usually convenient), $\dot{m}$ is port mass-flow rate timeaveraged over one wave cycle time, $\langle\tilde{h}\rangle$ is massaveraged total enthalpy, $Q$ is the rate of energy addition to the wave rotor by volumetric heat generation (e.g., on-rotor combustion) or by heat transfer (neglected in this work). The specific power, $\epsilon_{s}$, is obtained by balancing angular momentum over one rotor revolution,

$\epsilon_{s}=(\gamma-1) \tilde{M}_{Q, i n}^{2}\left[\sum_{i} \frac{(\dot{m} v)_{i}}{(\dot{m})_{i n}}-\sum_{e} \frac{(\dot{m} v)_{e}}{(\dot{m})_{i n}}\right]$

where the rotor tip Mach number, $\tilde{M}_{\mathrm{Q}, \text { in }}$, and the massaveraged swirl coefficient, $\nu$, are defined in the Nomenclature. A balance of relative total energy over one rotor revolution provides an expression for the rate at which energy is added to the wave rotor by on-rotor combustion

$$
Q+\sum_{i}\left(\dot{m}<\tilde{h}^{\prime}>\right)_{i}-\sum_{e}\left(\dot{m}<\bar{h}^{\prime}>\right)_{e}=0
$$

where $\left\langle\tilde{h}^{\prime}\right\rangle$ is mass-averaged rothalpy and where $Q$ is zero when energy is added external to the wave rotor.

\section{Windage Loss}

Windage loss occurs in both pressure-exchangers and wave engines; however, windage scales with the cube of rotor tip speed and therefore can be an order-ofmagnitude higher in wave engines which operate with optimum equivalent tip speeds $\left(U_{\text {eq }}\right.$ ) near 600 to 750 $\mathrm{ft} / \mathrm{s}$ as compared to those of pressure-exchangers, near 250 to $300 \mathrm{ft} / \mathrm{s}$. Windage reduces net shaft power so that $\dot{W}_{\text {net }}=\left|\dot{W}_{s}\right|-\dot{W}_{\tau}$ where $\dot{W}_{\tau}$ is the power lost to windage. Pearson. ${ }^{2}$ estimated shroud windage losses in his machine to reduce net shaft power by $4 \%$. Influenced by the models described by Roelke, ${ }^{14}$ the specific windage power $\left(\epsilon_{\tau} \equiv \dot{W}_{\tau} /(\dot{m} \tilde{h})_{i n}\right)$ is estimated in the present work using

$$
\epsilon_{\tau}=\frac{(\gamma-1) \tilde{M}_{Q, i n}^{2}\left(1-f_{b}\right)\left(1+f_{W}\right) \frac{R_{T}}{L_{T}} c_{\tau} \sum_{k=1}^{4} \Delta_{k}}{n \alpha_{m} \cos \beta_{R}\left(1-\left(\frac{R_{H}}{R_{T}}\right)^{2}\right)\left(\frac{\delta_{G}}{L_{T}} \tilde{M}_{Q, i n} T R^{-\frac{1}{2}} \operatorname{Re}{ }_{L_{\tau}}\right)^{\frac{3}{4}}}
$$

where $\alpha$ is the mass discharge fraction derived in previous ${ }^{m}$ work ${ }^{12,13}$ and $\Delta_{k}(k=1,4)$ and other geometric parameters are defined in the Nomenclature. 


\section{Wave Engine Aerodynamic Design}

In the case of a pressure-exchanger, the design intent is to maximize the pressure ratio, $P R$, at the baseline engine temperature ratio, $T R$, and mass flow rate. For the wave engines of this study, $P R, T R$, and the mass flow rate are dictated by the baseline engine, and wave engine net shaft power is maximized. Although the wave rotor performance is calculated in this work using the one-dimensional model described above, it is insightful to consider an ideal wave rotor characteristic in order to contrast the pressure-exchanger and wave engine topping approaches and to identify key design parameters.

\section{Wave Rotor Characteristic}

Consider the schematic diagram of the two-port wave rotor with on-rotor combustion (or valvedcombustor ${ }^{15}$ ) shown in Fig. 1c. The pressure ratio of this wave rotor in the isentropic limit ${ }^{\mathrm{13}}$ is given by

$$
P R^{m}=\left(\frac{H R\left(1-f_{b}\right)}{\alpha_{m}}\left[\left(1-\gamma \alpha_{e}\left(1-\frac{1}{\left(1-f_{b}\right) H R^{\prime}}\right)\right)^{\frac{1}{\gamma}}-\left(1-\alpha_{m}\right)\right]\right)^{\Gamma}
$$

where $\alpha$ and $\alpha$ are respectively the fractions of mass and energy dischárged from a rotor passage as it moves past the exhaust port (both are solely functions of the expansion fan strength, $\epsilon$, and $\gamma$ ), ${ }^{13} f_{\mathrm{b}}$ is the bleed fraction of HPT cooling air extracted from the wave rotor, and the relative total enthalpy ratio is

$$
H R^{\prime}=\frac{H R-\frac{\gamma-1}{2} \tilde{M}_{Q, i n}^{2}\left(2 v_{e x}-1\right)}{1-\frac{\gamma-1}{2} \tilde{M}_{Q, i n}^{2}\left(2 v_{i n}-1\right)} .
$$

Eqn. 8 provides an explicit expression for the ideal wave rotor pressure ratio as a function of specified total enthalpy ratio (or temperature ratio for a perfect gas with constant ratio of specific heats), inlet and outlet swirl coefficients, rotor Mach number, mass and energy discharge fractions (and hence expansion fan strength), coolant bleed fraction, and ratio of specific heats. The limiting case of a pressure-exchanger is obtained by setting the inlet and outlet swirl coefficients to unity. It is convenient for wave engines to invert Eqns. 8 and 9 to obtain

$$
\Upsilon \equiv \frac{1}{H R^{\prime}}=\left(1-f_{b}\right)\left(1-\frac{1}{\gamma \alpha_{c}}\left(1-\left(1-\alpha_{m}\left(1-\frac{\left(P R^{m}\right)^{\frac{1}{r}}}{\left(1-f_{b}\right) H R}\right)\right)^{\gamma}\right)\right)
$$

and

$$
\frac{\gamma-1}{2} \tilde{M}_{Q, i n}^{2}\left(2\left(v_{i n}-\Upsilon \nu_{e x}\right)-(1-\Upsilon)\right)=(1-\Upsilon H R) .
$$

Given a specified wave rotor pressure ratio, Eqns. 10 and 11 can then be used to set the swirl coefficients and the rotor Mach number, allowing the specific shaft power to be calculated (using Eqn. 5). This is essentially the approach used in the present work: the wave rotor pressure ratio is set by the baseline engine, and the turning schedule and rotor Mach number are parametrically varied to maximize shaft power output.

\section{Non-Dimensional Design Parameters}

The important non-dimensional operating parameters evident in Eqns. 10 and 11 are the absolute total enthalpy ratio $(H R)$, rotor-tip Mach number $\left(\tilde{M}_{\text {in }}\right)$, the inlet and outlet port mass-averaged swirl coeffincients $(v)$, the bleed fraction $\left(f_{b}\right)$, the mass $\left(\alpha_{j}\right)$ and energy discharge $(\alpha)$ coefficients, and hence the expansion fan pressure ratio $(\epsilon)$ and the ratio of specific heats $(\gamma)$. The swirl coefficients $(v)$ depend on the relative velocities $\left(w_{\theta}\right)$ set by the wave diagram and the principal expansion fan strength $(\epsilon)$, and the inlet and outlet blade angles ( $\beta_{L}$ and $\beta_{R}$, respectively).

The wave rotor flow capacity can be expressed as

$$
\frac{\dot{m}_{i n}\left(\left((\gamma-1) \bar{h}_{i n}\right)^{1 / 2} / \gamma \bar{p}_{i n}\right)}{\pi R_{T}^{2}\left(1-\left(\frac{R_{u}}{R_{T}}\right)^{2}\right)}=\frac{n \tilde{M}_{Q, i n}{ }^{\alpha}{ }_{m} \cos \beta \beta_{\alpha}\left(\tilde{p}_{r, V} / \tilde{p}_{i n}\right)\left(\tilde{h}_{i n} / \tilde{h}_{r, V}\right)}{2 \pi\left(\frac{R_{T}}{L_{T}}\right)\left(1-f_{b}\right)\left(1+f_{W, e x}\right)}
$$

where the left hand side of is the wave engine corrected mass flow rate per rotor annulus flow area. Important non-dimensional geometric parameters evident from Eqn. 12 are the hub-to-tip ratio, $R_{H} / R_{T}$, the tip-radiusto-chord ratio, $R_{T} / L_{T}$, the blade blockage factor, $f_{\text {wee }}$ and the blade angle at the exhaust-port-end of the machine. The parameter $n$ indicates the number of wave rotor cycles experienced by a given passage during one rotor revolution. For example, an $n=2$ wave rotor has two duct sets and each wave cycle occupies $\pi$ radians of a rotor revolution. The ratio of the chord length to pitch at the tip (or passage aspect ratio), $L_{T} / L_{P}$, is related to $R_{T} / L_{T}$ by

$$
\frac{L_{T}}{L_{P}}=\left(2 \frac{R_{T}}{L_{T}} \sin \left(\frac{\pi}{\left(1+f_{W}\right) n_{B}}\right)\right)^{-1}
$$

where $n_{B}$ is the number of rotor blades and $f_{W}$ is the local blade blockage factor. $R_{T} / L_{T}$ can be expressed as

$$
\frac{R_{T}}{L_{T}}=\frac{n \tilde{M}_{Q, \text { in }}{ }^{\tau_{\text {cycle }}\left(\tilde{h}_{\text {in }} / \tilde{h}_{r, V}\right)^{1 / 2}}}{2 \pi}
$$

where the non-dimensional cycle time, $\tau_{\text {cycle }}$, is dictated by the wave cycle (and is between 9.5 and 10 for the cycles of the present work) and $\tilde{h}_{i n} / \tilde{h}_{r, V}=\chi^{-1}$ (where $\chi$ is defined in the Nomenclature). 


\section{Design Procedure}

Performance calculation. The wave engine designpoint performance levels are calculated using the macroscopic balance code described in Ref. 12. TR, $\epsilon$, $L_{T} / L_{P}, L_{W} / L_{P}, R_{H} / R_{T}, f_{b}, \tilde{T}_{i n}, \tilde{p}_{i n}, \tilde{M}_{Q, i n}, \beta_{L}, \beta_{R}$, $n$, and $L_{T}$ are input variables, of which $T R, \tilde{T}_{i n}$, and $\tilde{p}_{i n}$ are set by the baseline engine constraints, as is the wave rotor pressure ratio, $P R$, and mass flow rate, $\dot{m}_{\text {in }}$. Influenced by an earlier study, ${ }^{12}$ the hub-to-tip ratio, $R_{H} / R_{T}$, is set at 0.667 and the expansion fan pressure ratio is $\epsilon=0.4$ in this study. The constant ratio of specific heats, $\gamma$, is evaluated at $\tilde{T}_{T}=\tilde{T}_{e x}=T R \cdot \tilde{T}_{i n}=T R \cdot \tilde{T}_{C}$. Having set the input variables, there is a family of $\beta_{L}, \beta_{, R}$, and $\tilde{M}_{\Omega \text {,in }}$ triads that provide the specified $P R$ and $\dot{m}_{i n}$.

Geometry optimization. For each of the wave cycles considered in the next section, the rotor passage aspect ratio, $L_{T} / L_{P}$, and chord length, $L_{T}$, were parametrically varied to maximize the net shaft power, $\dot{W}_{\text {net }}$, at zero inlet blade angle $\left(\beta_{L}=0\right.$, or $\left.v_{\text {in }}=1\right)$ and one cycle per rotor revolution $(n=1) . \dot{W}^{\circ}$ in plotted as a function of rotor length, $L_{T}$ in Fig. 4 . $^{\text {nef }}$ in the case of the four-port cycles, the external burner pressure drop required by the wave cycle was allowed to vary as indicated; however, a $6 \% \Delta \tilde{p} / \tilde{p}$ was considered minimum for a viable wave engine topping unit. Optimum $L_{T}$ and $L_{T} / L_{P}$ are provided, along with other geometry design parameters in Table 1 .

The wave engines considered in the next section are designed to top an example small turboshaft engine considered in earlier work ${ }^{9}$ with $T R(=H R)=2.213$, using $\tilde{T}_{T}=\tilde{T}_{\text {ex }}=2390 \mathrm{R}, \tilde{T}_{C}=1080 \mathrm{R}, \tilde{p}_{\text {in }}=7.77 \mathrm{~atm}$., and mass flow rate $=5.8 \mathrm{lb} / \mathrm{s}$. The pressure ratio across the wave engine is required to be $P R=0.96$, reflecting the baseline engine $4 \%$ burner pressure loss, and the baseline engine requires $4.9 \% \mathrm{HPC}$ bleed for HPT cooling. While in the pressure-exchanger topping approach this cooling flow necessarily came from within the wave rotor, ${ }^{9}$ in the wave engine approach HPC discharge is of sufficient pressure to inject into the HPT; therefore, the compressor discharge directed to the wave engine is $4.755 \mathrm{lb}_{\mathrm{m}} / \mathrm{s}$.

\section{Example Wave Engine Topping Units}

The wave engines considered in this section operate with one of three wave cycles: a two-port "valvedcombustor" ${ }^{15}$ cycle, a through-flow four-port cycle, or a reverse-flow four-port cycle. The low pressure ports of the four-port cycles serve the same purpose as the two ports of the valved-combustor (see Fig. 1c): to discharge high temperature, high pressure burned gas to the high pressure turbine and draw relatively cold, fresh air into the wave rotor from the compressor. The high pressure ports of both four-port cycles carry gas to and from conventional external burners. Burning occurs internal to the rotor passages in the two-port valved-combustor. The through-flow and reverse-flow four-port cycles have been the subject of much past and current research and are described in detail elsewhere (e.g., see Refs. 9 and 12). Pressure-exchangers using variants of the two-port cycle with on-rotor combustion have been studied most recently by Nalim and Paxson. ${ }^{16}$

\section{Two-Port "Valved-Combustor"}

A schematic diagram of a valved-combustor, ${ }^{15}$ or two-port cycle, with net shaft power extraction is provided in Fig. 1c. A fuel/fresh air mixture enters the rotor through the inlet port, is burned internal to the rotor, and is then discharged to the exhaust port. The charging and discharging processes occur efficiently using the gas dynamics represented by the wave diagram in Fig. 1c (after Klapproth ${ }^{4,15}$ ). The two-port nondimensional cycle time, $\tau$ (see Eqn. 14) is obtained in the present work by adding an assumed nondimensional burn time to the calculated non-dimensional time required to propagate the gas dynamic waves of the two-ports (cf. description of timing the low pressure ports of four-port wave rotors ${ }^{12}$ ). The assumed nondimensional burn time is 3.5 , and is chosen simply to keep the two-port and four-port non-dimensional cycle times (cf. Ref. 12) approximately the same $(\approx 10)$. It is unknown at this point whether this is a realistic burn time. In practice, extremely long burn times would increase the fraction of the wave rotor cycle (i.e., $\tau_{L}$ and $\tau_{f}$ ) during which the rotor flow annuli face the endwalls rather than ports, thus increasing windage losses; further, because rotor-to-casing leakage (neglected here) negates pressure rise during the internal combustion process, burn times should be as short as possible. In the present study the fresh air penetrates only to 32 to $35 \%$-chord and therefore the assumed effective average non-dimensional burn front speed is $\propto$ 0.1 , consistent with a deflagration burn front (cf. Nalim and Paxson ${ }^{16}$ ).

One cycle per revolution $(n=1)$. The optimum rotor length (see Fig. 4) is near 7 inches at an optimum passage aspect ratio of 11 . The variation of net shaft power and camber angle $\left(\Delta \beta=\beta_{L}-\beta_{R}\right)$ are plotted as functions of the inlet (left) blade angle in Fig. 5. The maximum net shaft power is $145 \mathrm{hp}$ and occurs at $\beta_{1}=-5^{\circ}, \quad \beta_{R}=-36.5^{\circ}\left(\Delta \beta=31.5^{\circ}\right)$ with $\tilde{M}_{\text {, in }}=$ 0.625 . Other rotor design values are summarized in Table 1. The $n=1$ valved-combustor concept has the evident problem that the fresh (relatively cold) air travels only 30 to $35 \%$ through the passage so that 65 to $70 \%$ of the passage is not cooled; that is, the $n=1$ valved-combustor (of this study, however see work of Nalim and Paxson ${ }^{16}$ ) is not fully self-cooling--a key, enabling feature of wave rotors for topping cycles. 
Table 1. Optimized geometry and performance levels of wave engines using three wave cycles and one and two duct-sets per rotor at baseline engine operating conditions: $T R=2.213, P R=0.96$, $\dot{m}=4.755 \mathrm{lb} / \mathrm{s}, \tilde{T}_{i n}=1080 \mathrm{R}, \tilde{p}_{\text {in }}=7.77 \mathrm{~atm}$; baseline engine SFC $=0.622 \mathrm{lb}$-fuee $/ \mathrm{hr}-\mathrm{hp}$ at $576 \mathrm{hp}$; fixed wave rotor design parameters include: $\epsilon=0.4, R_{H} / R_{T}=0.6 \overline{6}, f_{\mathrm{W}, \text { ex }}=0.08$, and $\gamma=1.315$.

\begin{tabular}{|c|c|c|c|c|c|c|}
\hline \multirow{2}{*}{$\frac{\text { Parameter }}{n}$} & \multicolumn{2}{|c|}{ Valved-Combustor } & \multicolumn{2}{|c|}{ Reverse-flow four-port } & \multicolumn{2}{|c|}{ Through-flow four-port } \\
\hline & 1 & 2 & 1 & 2 & 1 & 2 \\
\hline$L_{T}$ (inches) & 7 & 3.5 & 7.0 & 3.5 & 5.60 & 2.80 \\
\hline$R_{T}$ (inches) & 416 & 3.94 & 4.42 & 3.91 & 3.95 & 3.95 \\
\hline$L_{P} L_{P}$ & 11 & 11 & 12 & 12 & 10 & 10 \\
\hline$R_{T} / L_{T}$ & 0.594 & 1.125 & 0.631 & 1.118 & 0.705 & 1.410 \\
\hline$\therefore \quad \tilde{\boldsymbol{M}}_{\mathbf{Q}, \text { in }}$ & 0.625 & 0.579 & 0.660 & 0.577 & 0.716 & 0.716 \\
\hline$\beta_{1}$ (degrees) & -50 & $18.1^{*}$ & -15.0 & $18.0^{*}$ & $12.0^{*}$ & $11.9^{*}$ \\
\hline$\beta_{R}$ (degrees) & -36.5 & -18.1 & -45.9 & -18.0 & -12.0 & -11.9 \\
\hline$\Delta \beta$ (degrees) & 31.5 & 36.2 & 27.9 & 36.0 & 24.0 & 23.8 \\
\hline$\left|\dot{W}_{s}\right|$ (hp) & 164.9 & 139.6 & 250.5 & 190.3 & 248.4 & 246.3 \\
\hline$\dot{W}_{\tau}(\mathrm{hp})$ & 19.7 & 6.71 & 23.2 & 5.60 & 12.5 & 8.82 \\
\hline$\dot{W}_{\text {net }}$ (hp) & 145.1 & 132.9 & 227,2 & 184.6 & 236.0 & 237.5 \\
\hline Burner $\Delta \tilde{p} / \tilde{p}(\%)$ & $n / a$ & $\mathrm{n} / \mathrm{a}$ & 6.50 & 9.84 & 6.62 & 6.65 \\
\hline Peak cycle temperature $(R)$ & 2887 & 2800 & 2827 & 2731 & 3021 & 3020 \\
\hline Peak cycle pressure ${ }^{a}(\mathrm{~atm})$ & 17.2 & 15.7 & 20.9 & 17.2 & 22.3 & 22.3 \\
\hline Self-cooling fraction (\%) & 32.2 & 68.1 & 31.4 & 68.2 & 100 & 100 \\
\hline SP-enhancement ${ }^{\mathrm{b}}(\%)$ & +25.2 & +23.1 & +39.4 & +32.1 & +41.0 & +41.2 \\
\hline SFC-enhancement $t^{c}(\%)$ & -15.6 & -14.9 & -22.0 & -19.3 & -22.9 & -23.1 \\
\hline
\end{tabular}

*Symmetric blades.

${ }^{2}$ Peak temperature and pressure of pressure-exchanger-topped engine are $2972 \mathrm{R}$ and $25.6 \mathrm{~atm}$, respectively (Ref. 9).

"Specific-power-enhancement $=(576 \mathrm{hp}+\dot{W}) / 576 \mathrm{hp}$. SP-enhancement by pressure-exchanger topping is $23.6 \%$ (Ref. 9).

${ }^{\mathrm{S} S F C}$-enhancement (estimated using Eqn. 15). ${ }^{\text {net }}$ SFC-enhancement by pressure-exchanger topping is $-19.3 \%$ (Ref. 9).

Further, the valved-combustor potentially has large endwall fractions, $\tau_{L}$ and $\tau_{R}$, leading to high endwall windage loss. Given the assumed burn time of this work, windage loss reduces the valved-combustor output by $\dot{W}_{\tau}=20 \mathrm{hp}$, from $\left|\dot{W}_{s}\right|=165 \mathrm{hp}$ to $\dot{W}_{\text {net }}=145 \mathrm{hp}$ (i.e., by $12 \%$ ).

Two cycles per revolution ( $n=2$ ). If $n$ is increased from 1 to $n \geq 2$, with a concomitant factor $n$ reduction in chord length, $L_{r}$, the gross shaft power, optimum nondimensional design parameters, and blade angles remain unchanged; however, by decreasing the rotor length, the power loss to windage, $\dot{W}_{\tau}$, is reduced. For an $n=2$ valved-combustor, the optimum $L_{r}$ is halved (from 7 to 3.5 inches) and the fraction of power lost to windage is reduced from $12 \%$ to $9.7 \%$. With an $n=2$ approach, the two cycles can be mirror images of one another; fresh air enters the rotor from both ends and therefore provides effective cooling to nearly $70 \%$ of the rotor.
This approach helps address the required rotor selfcooling issue; however, symmetric blading (i.e. $\boldsymbol{\beta}_{L}=-\boldsymbol{\beta}_{R}$ ) is required. Further, because fresh air is ingested, and hot gas is discharged, at both ends of the rotor, complicated, likely impracticable, ducting is introduced to the engine layout. The design point for an $n=2$, symmetric-blade cycle is noted in Fig. 5 and Table 1.

\section{Reverse-Flow Cycle}

The reverse-flow, four-port cycle was used in early experimental research aimed toward topping gas turbine engines with wave engines ${ }^{3,4}$ and pressure-exchangers. ${ }^{17}$ The reverse-flow cycle shares a feature with the twoport valved-combustor in that the fresh air penetrates only part way (e.g., $35 \%$ ) into the rotor; it then reverses and is discharged to the burner at the inlet end of the rotor. As a result, similar to the valved-combustor of 
this study, an $n=1$ reverse-flow cycle is not fully selfcooling. Unlike the valved-combustor, the mass flow rate of cycle high pressure and temperature air from the burner re-enters the wave rotor and contributes significantly to wave engine power production.

One cycle per revolution $(n=1)$. The reverse-flow cycle optimizes out at $L_{T}=7$ inches and $L_{T} / L_{P}=12$. The net shaft power of the $n=1$ reverse-flow cycle is plotted as a function of inlet blade angle in the dashed curve of Fig. 5. The variation of camber angle as a function of inlet blade angle is identical to that of the valved-combustor. The maximum net shaft power is $228 \mathrm{hp}$ and occurs at $\beta=-18^{\circ}, \quad \beta_{R}=-45.9^{\circ}$ $\left(\Delta \beta=27.9^{\circ}\right)$ with $\tilde{M}_{0 \text { in }}=0.672$. This compares to the $145 \mathrm{hp}$ maximum power obtained for the two-port. $10 \%$ of the gross shaft power is consumed by windage loss at this design point. Other parameters are presented in Table 1 . The $n=1$ cycle with symmetric-blading was used to generate Fig. 3 by varying the camber angle $(\Delta \beta)$ from zero (pressure-exchanger-limit) through eighty degrees. Though beyond the scope of this paper, one can envisage other multi-port arrangements based on the basic $n=1$, reverse-flow concept--for example, a six-port in which some of the compressed fresh air discharged to the burner is re-injected at the hot (right) end of the machine.

Two cycles per revolution $(n=2)$. As in the valved-combustor, the $n=1$ reverse-flow cycle is not fully self-cooling. An additional $35 \%$ of the rotor can be self-cooled by following the reverse-flow cycle with its mirror-image.' This approach requires the blades to be symmetric $\left(\beta_{L}=-\beta_{R}\right)$ about the center of the machine. With $n=2$, the optimum rotor length is $L_{T}=$ 3.5 inches. The net shaft power is $182 \mathrm{hp}$ at $\beta_{L}=-\beta_{R}=18.1^{\circ}\left(\Delta \beta=36.2^{\circ}\right)$ and $\tilde{M}_{0 \text { i }}=0.578$. It is ${ }^{L}$ again noted that likely impracticable ducting is required in this approach and the middle $30 \%$ of the rotor remains to be actively cooled.

\section{Through-Flow Cycle}

The through-flow cycle is distinct from the two-port and reverse-flow cycles in that the fresh air traverses the rotor and exits at the opposite end to the burner. The rotor self-cooling is successfully accomplished with $n=$ 1. A fraction of burned gas is recirculated through the burner; the mass flow rate through the high pressure ports and the external burner is typically 1.5 to 1.8 times higher than that through the low pressure ports. As in the reverse-flow cycle, the upper loop flow produces a substantial fraction of the wave engine power. Note in Fig. 4 that shaft power of the through-flow cycle increases monotonically with chord length to a maximum near 8 inches; however, the rotor length is dictated by the minimum allowable burner pressure drop fraction constraint in this case rather than by maximizing net shaft power. A limiting value of $\Delta \tilde{p} / \tilde{p}$ $=6.5 \%$ for the length optimization at $\beta_{L}=0^{\circ}$ so that a $6 \%$ goal would be met at all blade angles considered in Fig. 5.

One cycle per revolution $(n=1)$. The solid curve of Fig. 5 describes the net shaft power as a function of the inlet biade angle, $\beta_{L}$, at $L_{T}=5.6$ inches and $L_{T} / L_{P}$ $=10$. In contrast to the reverse-flow two-port cycles, the optimum performance in the through-flow engine naturally occurs when the blades are symmetric. The maximum net shaf power is $236 \mathrm{hp}$ at $\beta=-\beta_{R}=12^{\circ}$ $\left(\Delta \beta=24^{\circ}\right)$ with $\tilde{M}_{0 i n}=0.716$. At this point the power lost to windage is $12.5 \mathrm{hp}$, or $5 \%$ of the $\left|\dot{W}_{S}\right|=$ $248 \mathrm{hp}$ gross wave engine shaft power. The camber angle variation with inlet blade angle is qualitatively the same as the for the valved-combustor and the reverseflow wave engines; however, the through-flow camber angle is lower, reflecting the higher rotor Mach number.

Two cycles per tevolution $(n=2)$. Although the through-flow cycle is seif-cooling with $n=1$, engine integration issues--for example, the wave rotor-to-HPT transition--may in fact point toward an $n=2$ approach. With $n=2$, the symmetric blade, $L_{T}=2.80$ inches, $L_{d} / L_{p}=10$, wave engine produces net shaft power of $238 \mathrm{hp}$ at $\beta=-\beta_{R}=11.9^{\circ}\left(\Delta \beta=24^{\circ}\right)$ with $\tilde{M}_{\text {, }}=$ 0.716 , and the windage power loss fraction is $3.6 \%$. The burner pressure drop fraction at this point is $6.7 \%$.

\section{Comparison of Cycles}

The strength of the valved-combustor concept is that on-rotor combustion--if indeed shown to be a viable means of energy addition--eliminates the need for the high pressure loop ducting and the external burners (see Ref. 9). Its weaknesses include heat addition at low pressure and high (10 to $15 \%$ ) windage loss fractions due to high $\tau$ and $\tau$. The $n=1$ cycle cools only $35 \%$ of the inlet-end of the rotor. The mirror-image, $n$ $=2$ cycle cools all but the middle $30 \%$ of the rotor; however, this approach requires the fresh air to enter both ends of the rotor and the hot gas to be discharged from both ends of the rotor, making this concept not amenable to integration into gas turbine engines for aeronautical applications.

The strength of the reverse-flow cycle is the design flexibility offered by the substantial burner pressure drop margin (see Fig. 4). It is a strength of the reverse-flow cycle, in comparison to the through-flow cycle, that the air to the burner is fresh (and relatively cool). The reverse-flow cycle has the same rotor cooling issues as the valved-combustor. Again, the $n=2$ cycle is required to cool both ends of the rotor but introduces intractable ducting issues; indeed, the ducting problems are compounded by the two additional high pressure loops per wave cycle. The reverse-flow wave engine produces 35 to $60 \%$ higher net shaft power thar does 
Table 2. Through-flow four-port wave engine with two duct sets per rotor designed at $T R=2.213, P R=0.96$, $\dot{m}=4.755 \mathrm{lb}_{m} / \mathrm{s}, \tilde{T}_{\text {in }}=1080 \mathrm{R}, \tilde{p}_{\text {in }}=7.77 \mathrm{~atm}$, and $\gamma=1.315$.

\begin{tabular}{|c|c|c|c|}
\hline Parameter & Value & Parameter & Value \\
\hline Expansion fan pressure ratio, $\epsilon$ & 0.4 & Non-dimensional cycle time, $\tau_{\text {cyde }}$ & 9.55 \\
\hline Rotor tip Mach number, $\bar{M}_{Q, i n}$ & 0.696 & Reference time, ${ }^{t}$ & $0.0967 \mathrm{~ms}$ \\
\hline Passage aspect ratio, $L_{T} / L_{P}$ & 10 & Equivalent rotor tip speed, $U_{e q}$ & $753 \mathrm{ft} / \mathrm{s}$ \\
\hline Hub-to-tip ratio, $R_{H} / R_{T}$ & 0.666 & Angular speed, $\Omega$ & $31,428 \mathrm{rpm}$ \\
\hline$f_{w}$ at ends of rotor & 0.08 & Rotor blade count, ${ }_{b}^{n}$ & 80 \\
\hline Rotor chord length, ${ }_{T}$ & 2.88 inches & Rotor tip radius, $R_{T}$ & 3.96 inches \\
\hline Wave cycles per revolution, $n$ & 2 & Specific gross shaft power, $\epsilon_{s}$ & 0.124 \\
\hline Inlet blade angle, $\beta_{L}$ & $12.8^{\circ}$ & Wave engine gross shaft power, $\left|\dot{W}_{s}\right|$ & $258.1 \mathrm{hp}$ \\
\hline Exit blade angle, $\beta_{R}$ & $-12.8^{\circ}$ & Power consumed by windage loss, $\dot{W}_{t}$ & $8.33 \mathrm{hp}$ \\
\hline Bumer pressure drop fraction, $\Delta \tilde{p} / \tilde{p}$ & $6.0 \%$ & Wave engine net shaft power, $\dot{W}$ & $249.8 \mathrm{hp}$ \\
\hline
\end{tabular}

the valved-combustor due to work extraction from the high pressure loops.

The strength of the through-flow cycle is that the rotor is fully self-cooled. If the $n=2$ option is determined optimal by engine integration considerations (cf. Ref 11), ducting issues are complicated only to the extent that a second duct set is added: the fresh air is all ingested at the compressor end of the rotor and the hot air is all discharged at the turbine end of the rotor. The through-flow cycle affords little burner pressure drop margin however. If the burner loop ducting losses incurred in integrating the wave engine into the gas turbine engine are greater than those assumed in the present analysis, the particular through-flow wave cycle considered here may not be viable. A second (and related) weakness of the through-flow cycle is that the hot gas recirculated to the burner--although perhaps advantageous for combustion efficiency--significantly raises the burner inlet temperature over that of the reverse-flow cycle. This problem can be avoided by going to the basic five-port cycle used by Pearson; ${ }^{1}$ however, the wave engine must then be aerodynamically matched with the compressor, the HPT, and the LPT. The five-port approach, though attractive, is beyond the scope of the current work. Considering the net shaft power levels and rotor self-cooling and ducting issues, the through-flow, four-port cycle is used below to estimate gas turbine engine performance level enhancement offered by wave engine topping.

\section{Through-Flow Wave Engine Design}

To take full advantage of the allowable $6.0 \%$ burner $\Delta \tilde{p} / \tilde{p}$, the rotor length of the $n=1$ rotor is increased from 5.6 (used for the parametric study above) to 5.75 inches while the $n=2$ rotor is increased from 2.80 to 2.88 inches, both at $L_{T} / L_{p}=10$. The net shaft power levels at these new design points are plotted in Fig. 5. Detailed design-point information for the $n=2$ throughflow four-port, wave engine with symmetric blading is provided in Table 2. The net shaft power is $250 \mathrm{hp}$ at $\beta_{L}=-\beta_{R}=12.8^{\circ} \quad\left(\Delta \beta=25.6^{\circ}\right)$ with $\tilde{M}_{Q_{\text {in }}}=0.696$. The power lost to windage at this point is $3.2 \%$ of the gross power $(258 \mathrm{hp})$. The final design shows $R_{T}=3.96$ inches, $L_{T}=2.88$ inches, and 80 rotor blades (or 40 blades per wave cycle). The rotor Mach number $\left(\tilde{M}_{Q, \text { in }}=0.696\right)$ and corresponding equivalent tip speed $(753 \mathrm{ft} / \mathrm{s})$ are not exceptionally high. The rotor Mach number based on the peak temperature is approximately 0.44 . This being the case, the work reported in Ref. 18 suggests that centripetal- and Coriolis-accelerationinduced skewing at hot gas/cold gas interfaces might impact the flow dynamics. The rotor angular speed is $31,428 \mathrm{rpm}$, very near the shaft speed of the LPT in the small gas turbine engine considered.

\section{Wave-Engine-Enhancement of Gas Turbine Engine}

The $n=2$, through-flow, four-port wave engine produces $258 \mathrm{hp}$ gross shaft power $\left(\epsilon_{s}=\mathbf{0 . 1 2 4}\right)$ of which $8.3 \mathrm{hp}$ is consumed by windage, leaving $250 \mathrm{hp}$ net shaft power $\left(\epsilon_{i e}=0.120\right)$. The wave-engine-topped engine is compare there to a pressure-exchanger-topped engine (see Ref. 9). The baseline engine produces 576 hp shaft power with a SFC of $0.622 \mathrm{lb}$ m-fue $/ \mathrm{hp}-\mathrm{hr}$. The specific-power-enhancement by the wave engine topping ( $826 \mathrm{hp} / 576 \mathrm{hp}-1$ ) is $43.4 \%$. This compares to $23.6 \%$ specific-power-enhancement by pressure-exchanger topping; ${ }^{9}$ the wave-engine-topped engine produces $16 \%$ 
more power than the pressure-exchanger-topped engine. The ratio of the SFC of the wave engine as compared to the baseline engine is estimated using

$$
\frac{S F C_{W E}}{S F C_{B A S E}}=\frac{1+\left(\epsilon_{S} /(T R-1)\right)}{1+\left(S F C_{B A S E} Q_{R} / c_{R}\right)\left(\epsilon_{n e t} /(T R-1)\right)}
$$

where $S F C$ is in $l b_{m-f u e l} / h p-h r, Q_{R}$ is the heating value of the fuel (e.g., $18,600 \mathrm{Btu} / \mathrm{lb}_{\mathrm{m}}$ ), $c_{R}$ is a conversion constant $(2545.6 \mathrm{Btu} / \mathrm{hp}-\mathrm{hr})$, and $T R$ is the wave engine temperature ratio (2.213). The wave engine topping enhances (reduces) the SFC by $24.0 \%$. This compares to a $19.3 \%$ SFC-enhancement by pressure-exchanger topping. ${ }^{9}$ Therefore, $\mathrm{SP}_{\mathrm{WE}} / \mathrm{SP}_{\mathrm{PE}}=1.16$ and $\mathrm{SFC}_{\mathrm{WE}} / \mathrm{SFC}_{\mathrm{PE}}$ $=0.942$. The SFC-enhancement-ratio less than unity contradicts the ideal Brayton cycle analysis. The higher wave engine efficiency is derived by operating at lower burner pressure drop fractions. The flow turning in the wave engine provides a degree- 6 f -freedoms to the wave rotor design that allows the wave cycle to match the burner loop pressure drop fraction (e.g., 6\% in this work). The wave cycle requires that the pressureexchanger operate with a large (10\% [through-flow] to $15 \%$ [reverse-flow; cf. Fig. 3]) burner loop pressure drop fraction at design point. Table 1 provides the SFC and specific power ratios of the other wave engine topping units. Note that the valved-combustor-topped engine produces virtually the same power as the pressureexchanger-topped engine, but with higher SFC $\left(\mathrm{SFC}_{\mathrm{WE}} / \mathrm{SFC}_{\mathrm{PE}}=1.05\right)$. The valved-combustor-topped cycle is less efficient than the pressure-exchanger-topped cycle, reflecting heat addition at lower pressures.

\section{Wave Engine Topping: Discussion}

The performance benefits by wave engine topping using the through-flow, four-port cycle exceed the already venerable benefits offered by pressureexchanger-topping. Evident negative and positive attributes of wave engine topping relative to pressureexchanger topping are summarized here.

\section{Negative Aspects}

Rotative speeds. Wave engine rotor equivalent speeds $\left(U_{e q}=650\right.$ to $\left.750 \mathrm{ft} / \mathrm{s}\right)$ are nearly 2 to 3 times higher than those of the pressure-exchangers $\left(U_{c q}=250\right.$ to $300 \mathrm{ft} / \mathrm{s}$ ). While pressure-exchangers optimize out near $\tilde{M}_{\text {in }}=0.25$ to 0.3 , wave engines optimize out near $\tilde{M}_{0, \text { in }}^{\Omega}=0.6$ to 0.7 . The higher the tip speed, the higher the centripetal blade loads; nonetheless, the wave engine tip speeds are low compared with modern turbomachinery equivalent tip speeds (e.g., $1700 \mathrm{ft} / \mathrm{s}$ ).

At the higher tip speeds, the windage loss in the wave engine is an order-of-magnitude higher than in the pressure-exchanger-- $3 \%$ to $15 \%$ of gross wave engine shaft power, depending on the design. Additionally, centripetal- and Coriolis-acceleration-induced skewing of interfaces between fresh air and burned gases leads to maldistribution of mass and energy within, and discharged from, the rotor and thus reduces machine performance. The skewing scales with the square of the rotor Mach number and will therefore be more extensive in the wave engine than in the pressure-exchanger.

Blade shapes. The potential simplicity in manufacturability offered by axially-bladed pressureexchangers is to some extent negated by the wave engine's more complicated blade profiling requirements.

Spinning. An issue not considered in this paper is that of mechanically integrating the wave engine with the engine shafts. An off-axis approach would introduce complicated porting and additional aerodynamic loss. On-axis operation naturally places the wave engine between the HPC and HPT. Ideally, therefore, the wave engine would spin on the high spool; however, the simple aerodynamic designs of the present work suggest that the wave engine optimally spins at LPT (low spool) speeds rather than at HPT (high spool) speeds.

\section{Positive Aspects}

HPT cooling bleed. The pressure ratio of the wave engine is dictated by the baseline engine in this study. In contrast to the pressure-exchanger-topping approach, the HPT cooling can be bled from the HPC, as in the baseline engine. This is a significant step toward integrating wave rotors into current engine configurations. Because $P R \geq 1$ in the pressureexchanger HPT cooling must be bled from the wave rotor topping loop; however, the higher pressure air extracted from the wave rotor is commensurately hotter than the nominal HPC discharge-cooling-air; it cools less effectively and therefore more is requixed. Modern engines require as much as $20 \%$ of the compressor discharge air to cool the first stage. The performance of the wave rotor is severely impacted by this bleed extraction (cf. Refs. 9, 10, and 13 and consider Eqn. 8 for the impact of bleed fraction on wave rotor performance). The bleed extraction diminishes the topping benefit and in some case makes pressureexchanger topping impracticable. ${ }^{10}$

Compactness/Weight. The wave engine spins faster than a pressure-exchanger and is typically half as long for the same mass flow rate requirement (cf. Eqn. 12) and the same number of wave cycles per revolution $(n)$. For example, the $n=2$ through-flow cycle has 2.88 inch rotor chord, or 2.86 inch rotor axial-length. A corresponding $(n=2)$ pressure-exchanger rotor is 6 or 7 inches in length. ${ }^{12}$ The outer diameter of the wave engine and pressure-exchanger are virtually the same. The short axial-lengths suggest minimal stretching of topped engines; this is expected to significantly impact 
engine added-weight. The wave-engine peak pressures are lower than those of the corresponding pressureexchanger (cf. Figs. 2 and 3). The lower peak pressure should significantly impact the weight of the wave engine and its associated ducting.

Speed match. Although the higher wave engine rotor tip speed is noted as a negative above, the wave engine shaft rotative speeds are very near the shaft speed of the LPT in the small gas turbine engine considered. Engine integration may be greatly simplified by this speed match.

\section{Summary}

Wave engine topping, under the constraints described in this work, promises significantly greater specific-power-enhancement than analogously applied pressure-exchanger topping. More heat is added to the wave-engine-topped cycle than to the pressureexchanger-topped cycle. A specific-power-enhancement of $43 \%$ is provided by the wave engine topping unit using the through-flow wave cycle; this compares to a specific-power-enhancement of $24 \%$ by the pressureexchanger topping unit. ${ }^{9}$ The ratio of the wave-engineand the pressure-exchanger-topped engine shaft powers is $16 \%$ which agress well with the $17 \%$ suggested by the ideal Brayton cycis analysis that helped motivate the study. Due to the shaft work extraction, energy is added to the wave-engine-topped cycle at lower pressure than in the pressure-exchanger-topped cycle; therefore, theoretically the SF(-enhancement of the wave engine topping is (e.g., 3\%) less than that effected by the pressure-exchanger topping. This was born out by the two-port wave engine with on-rotor combustion (i.e., the valved-combustor); however, in contrast to the ideal cycle analysis, the wave engines using reverse-flow and through-flow wave cycles provide as much or greater SFC-enhancement than do their pressure-exchanger counter-parts. For example, the SFC of the throughflow wave-engine-topped engine is $5.8 \%$ lower than that of the pressure-exchanger-topped engine. This apparent contradiction to the taeal thermodynamic anaiysis arises because the flow turning offers a degree-of-freedom to the wave rotor design process that allows the wave engine to match the gas turbine engine better at its design point than cas the pressure-exchanger.

Three wave rotor cycles were evaluated: two-port cycles with on-rotor combustion (valved-combustor) and reverse-flow and through-flow four-port cycles with external burners. The strengths and weaknesses of these cycles were discussed. The specific-power-enhancement effected by the valved-combustor equals that of the pressure-exchanger, but it offers less SFC-enhancement because heat is added to the cycle at lower pressure. The $n=1$ valved-combustor and reverse-flow cycles are not fully self-cooling. To cool both ends of the rotor, $n$ $=2$, mirror-image cycles with symmetric blading were considered. $72 \%$ of the blade surfaces can be selfcooled with the mirror-image approach; however, the ducting issues introduced by the need to port gases to/from both ends of the rotor are considered intractable. The reverse-flow and through-flow cycles produce significantly more power than the valved-combustor due to work extraction from the high pressure external burner loop. The through-flow wave rotor is fully selfcooling. The notable weaknesses of the particular through-flow cycle considered include low burner pressure drop margin and high burner inlet temperatures.

In addition to the impressive specific-power- and SFC-enhancement offered by the wave engine topping, significant steps toward wave rotor/gas turbine engine integration might be afforded by adopting the wave engine approach in lieu of the pressure-exchanger approach: a.) the HPT cooling again comes from the $\mathrm{HPC}$, in the same manner as in the baseline engine; b.) the wave engine and LPT spin at the same shaft speeds; c.) the upper pressure ratio (WPR) of a wave engine is lower than that of its pressure-exchanger counter-part-this will significantly impact materials, engineering design, weight, secondary cooling, and life; and finally, d.) the short wave engine rotor axial lengths suggest little length is added to the engine.

\section{References}

'Pearson, R. D., "A Gas Wave-Turbine Engine which Developed 35 H.P. and Performed over a $6: 1$ Speed Range," eds., Shreeve, R.P. and Mathur, A., Proc. 1985 ONRNAVAIR Wave Rotor Research and Technology Workshop, Report NPS-67-85-008, Naval Postgraduate Schoo, Monterey, CA, May, 1985, pp. 125-170.

${ }^{2}$ Pearson, R. D., "Performance Predictions for Gas Wave Turbines including Practical Cycles with Wide Speed Range," ibid., pp. 329-378.

${ }^{3}$ Klapproth, J. F., "Supercharged Turbowave Engines," Technical Information Series, R62FPD171, General Electric, Cincinnati, $\mathcal{O H}$, April, 1962.

${ }^{4}$ Mathur, A., 3985, "A Bris keview of the G. E. Wave Engine Program (1958-\$963)," eds., Shreeve, R.P. and Mathur, A., Prow 1985 ONRNAVAIR Wave Rotor Research and Technology Workskor, Report NPS-67-85008, Naval Postgraduate $\$$ ckoos, Konterey, CA, May, 1985, pp. 171-193.

${ }^{5}$ Coleman, R. R., "Sycle for a rrece Stage Ultrahigh Pressure Ratio Wave Turous Engine," AIAA-94-2725, June, 1994.

"Weber, H.E., "Wave Engine Aerothermodynamic Design," J. Engineering for Gas Turbines and Power, 114, Oct., 1992, pp. 790-796. 
${ }^{7}$ Weber, H. E., Shock Wave Engine Design, Wiley, New York, USA, 1995.

${ }^{8}$ Lear, W. E., Jr., and Kielb, R. P., "The Effect of Blade Angle Design Selection on Wave-Turbine Engine Performance," ASME-96-GT-259, June, 1996.

${ }^{9}$ Welch, G. E., Jones, S. M., and Paxson; D. E., "Wave Rotor-Enhanced Gas Turbine Engines," AIAA95-2799, July, 1995; also NASA TM-106998 and ARLTR-806.

${ }^{10}$ Jones, S. M. and Welch, G. E., "Performance Benefits for Wave Rotor-Topped Gas Turbine Engines," ASME-96-GT-075, June, 1996; also NASA TM-107193 and ARL-TR-1065.

${ }^{11}$ Snyder, P. H. and Fish, R. E., "Assessment of a Wave Rotor Topped Demonstrator Gas Turbine Engine Concept," ASME-96-GT-41, June, 1996.

${ }^{12}$ Welch, G. E., "Macroscopic Balance Model for Wave Rotors," AIAA-96-0243, Jan., 1996; also NASA TM-107114 and ARL-TR-925.

${ }^{13}$ Welch, G. E., "Wave Rotor Characteristic," NASA TM-4781, 1997; also ARL-TR-1280.



a. Meridional view

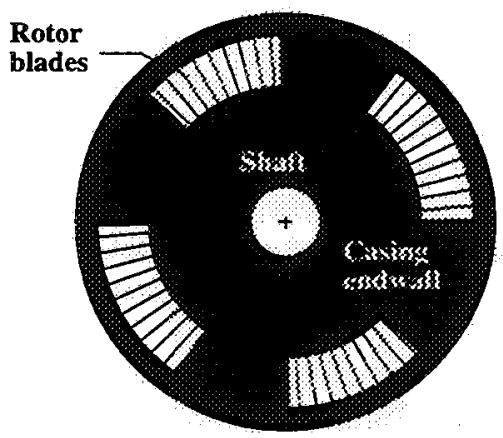

b. End view
${ }^{14}$ Roelke, R. J., "Miscellaneous Losses," ed. Glassman, A. J., Turbine Design and Application, NASA SP-290, Chapter 8, 1994, pp. 231-238.

${ }^{15}$ Goldstein, A. W., Klapproth, J. F., and Hartmann, M. J., "Ideal Performance of Valved-Combustors and Applicability to Several Engine Types," Transactions of the American Society of Mechanical Engineers, 80, July, 1958, pp. 1027-1036.

${ }^{16} \mathrm{Nalim}, \mathrm{M}, \mathrm{R}$. and Paxson, D. E., "A Numerical Investigation of Premixed Combustion in Wave Rotors," ASME-96-GT-116, June, 1996; also NASA TM-107242.

${ }^{17}$ Moritz, R., "Rolls-Royce Study of Wave Rotors 1965-1970," eds. Shreeve, R. P. and Mathur, A., Proc. 1985 ONR/NAVAIR Wave Rotor Research and Technology Workshop, Report NPS-67-85-008, Naval Postgraduate School, Monterey, CA, May, 1985, pp. 116-124.

${ }^{18}$ Larosiliere, L. M. and Mawid, M., "Analysis of Unsteady Wave Processes in a Rotating Channel," AIAA-93-2527, June, 1993.

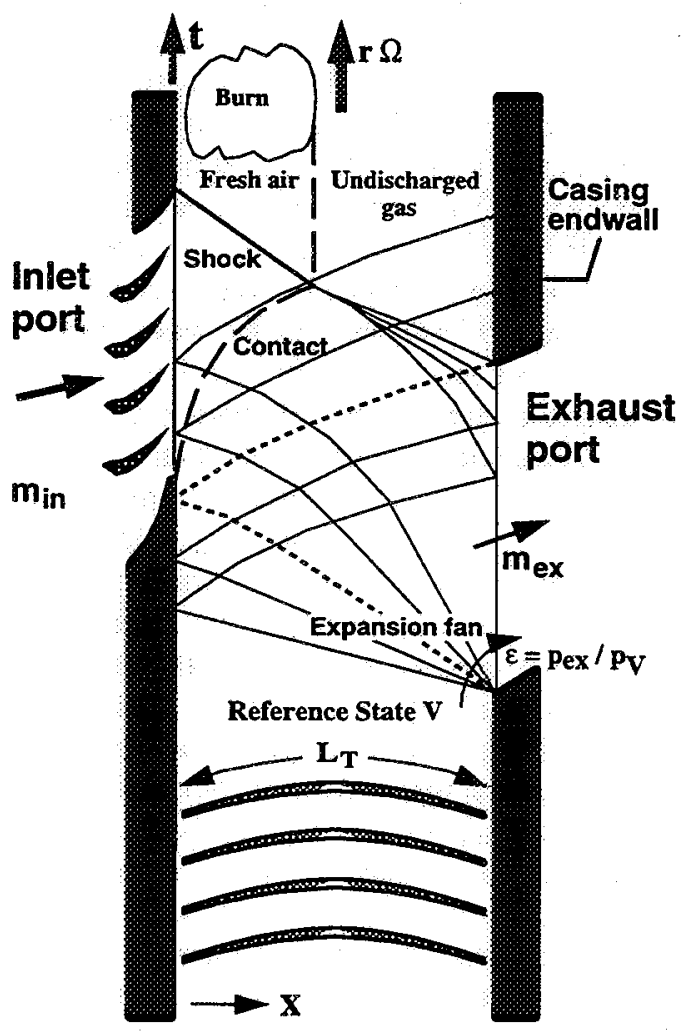

c. Unwrapped blade-to-blade view of the inlet and exhaust port portion of a two-port wave rotor with on-rotor combustion (valvedcombustor) showing a superimposed wave diagram and example wave engine blade shapes.

Figure 1. Wave engine schematic diagrams showing a.) meridional view, b.) end view, and c.) blade-to-blade view with wave diagram of an example two-port wave rotor with on-rotor combustion (valved. combustor). 


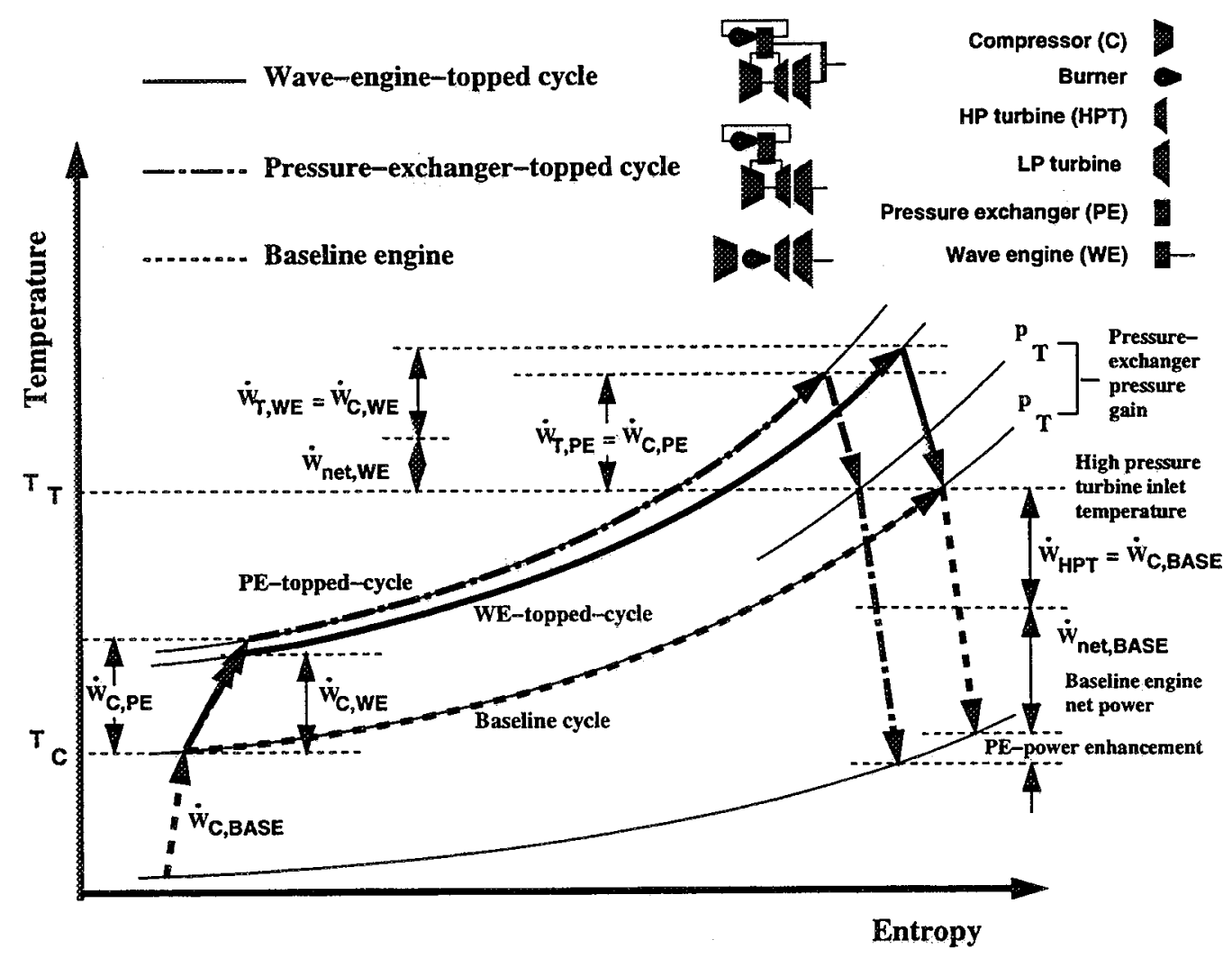

Figure 2. Temperature-entropy diagram showing thermodynamic cycles for wave-enginetopped engine, pressure-exchanger-topped engine, and baseline engine.

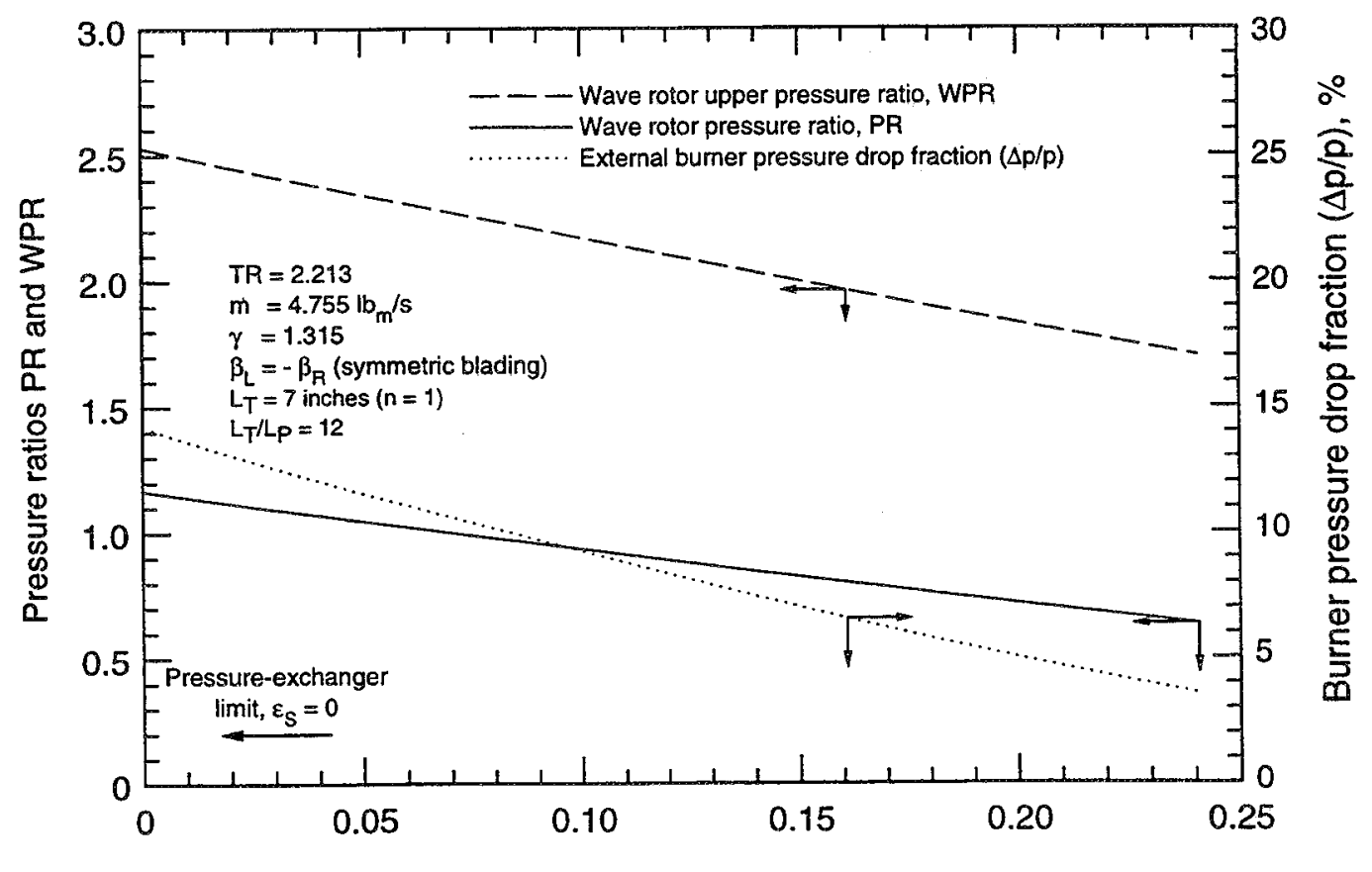

Wave rotor specific gross shaft power, $\varepsilon_{\mathrm{S}}$

Figure 3. Reverse-flow four port wave rotor upper pressure ratio, WPR, pressure ratio, PR, and burner pressure drop fraction, $\Delta \mathrm{p} / \mathrm{p}$, as a function of specific shaft power, $\varepsilon_{\mathrm{S}^{*}}$ 


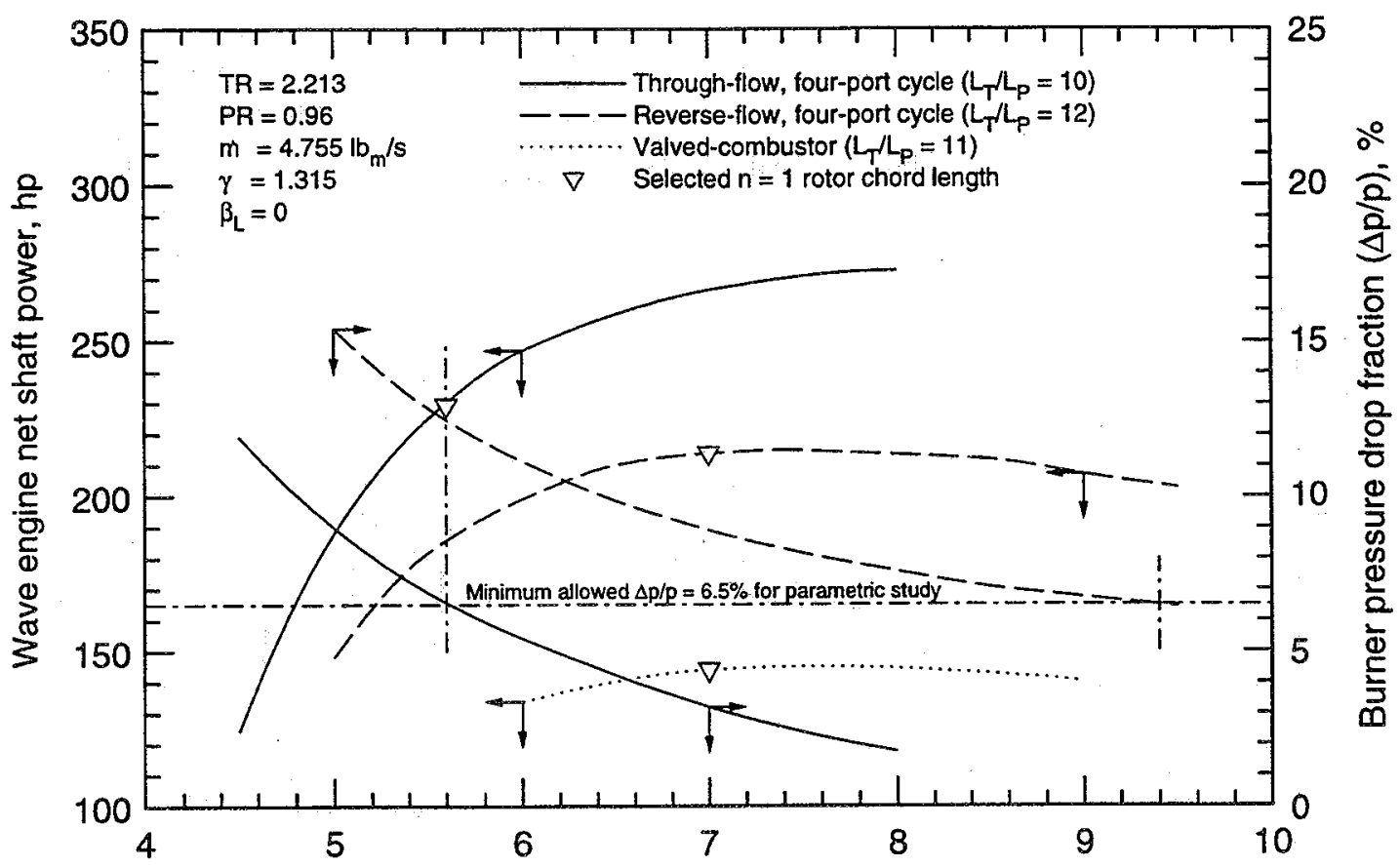

Rotor chord length $\left(L_{T}\right)$

Figure 4. Wave engine specific net shaft power and burner pressure drop fraction as functions of rotor chord length.

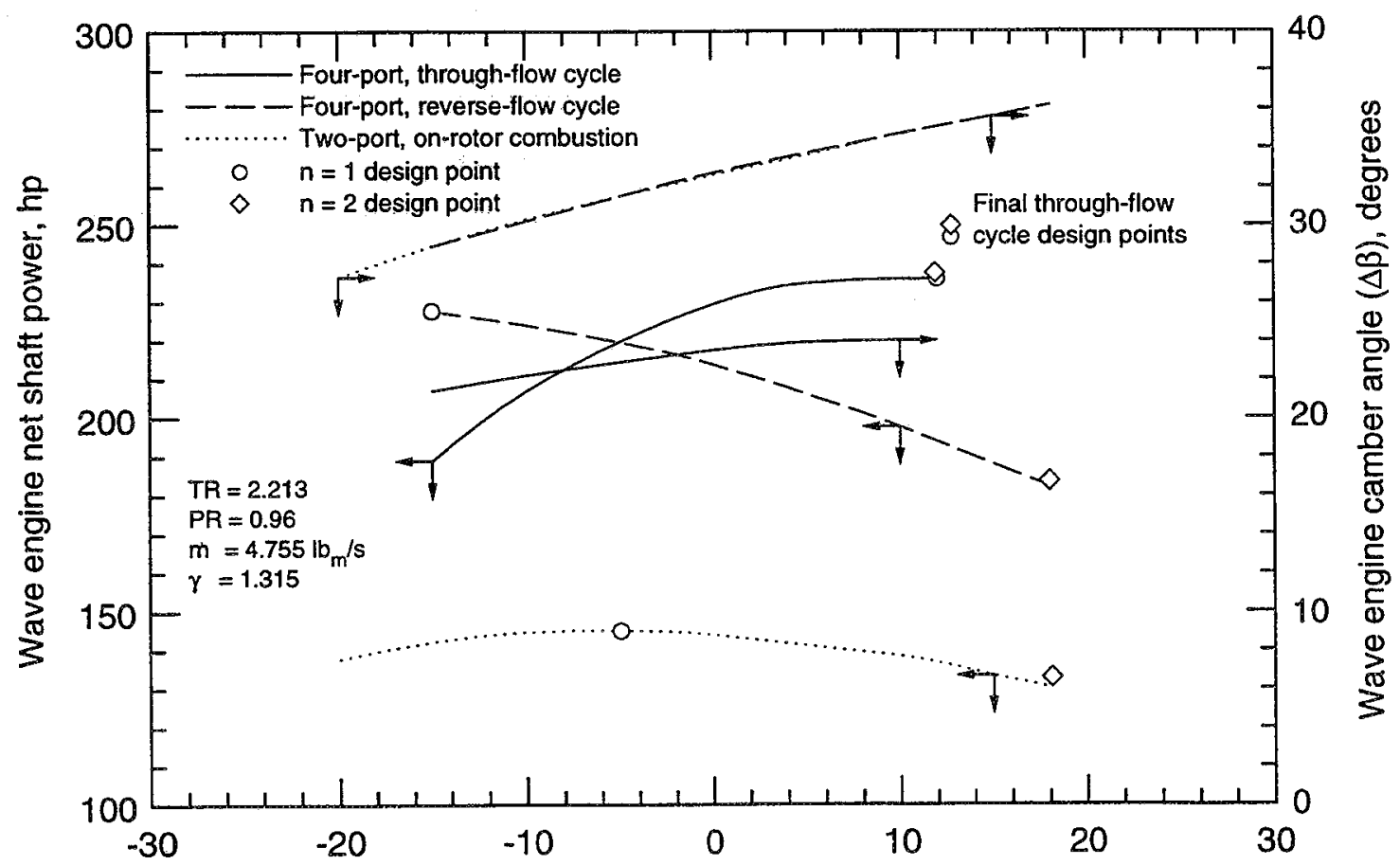

Blade angle at left end of rotor $\left(\beta_{\mathrm{L}}\right)$, degrees

Figure 5. Wave engine net shaft power and camber angle as functions of inlet blade angle, plotted for valved-combustor, reverse-flow and through-flow wave-cycle-based wave engines. 


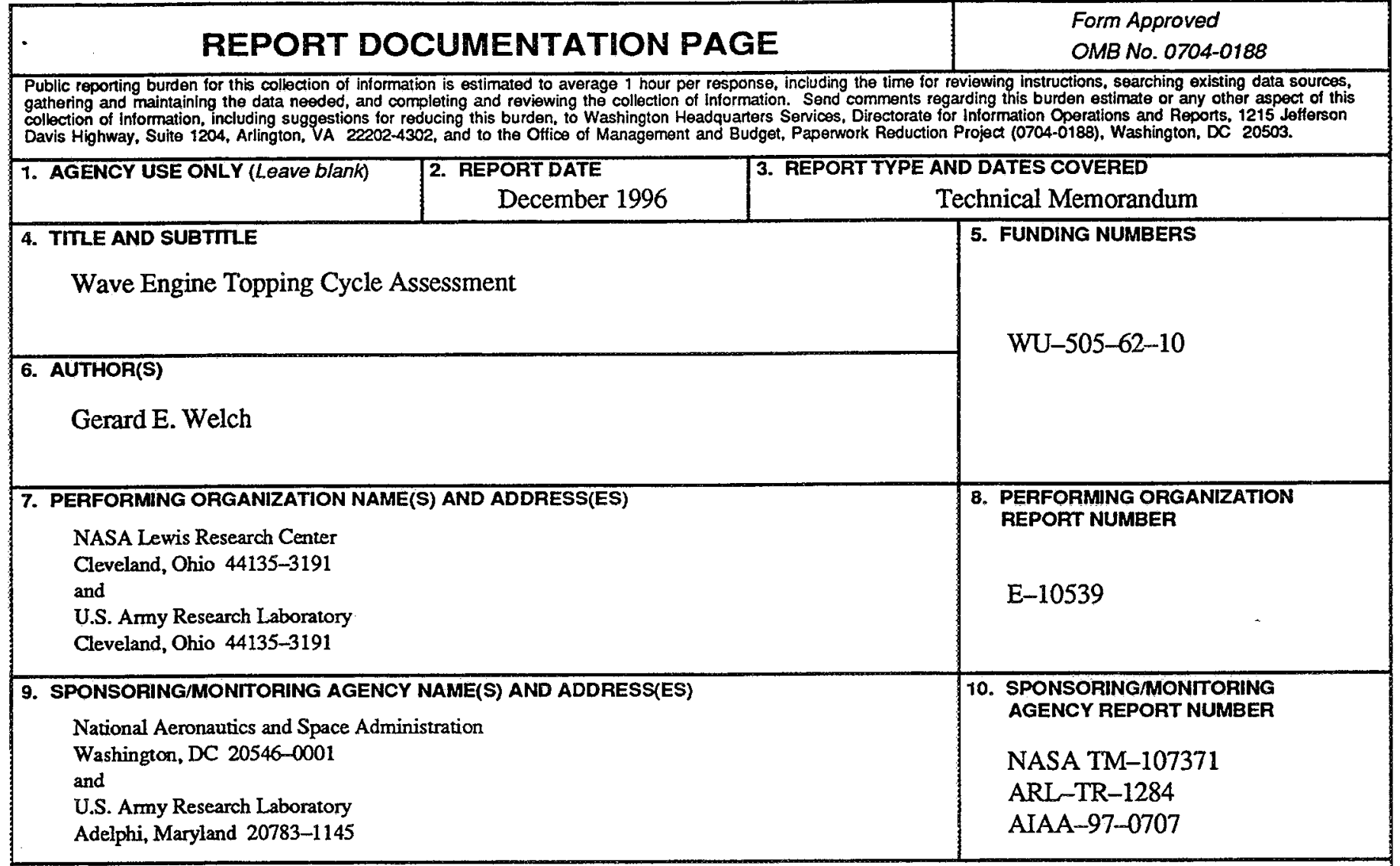

11. SUPPLEMENTARY NOTES

Prepared for the 35th Aerospace Sciences Meeting \& Exhibit sponsored by the American Institute of Aeronautics and Astronautics, Reno, Nevada, January 6-10, 1997. Responsible person, Gerard E. Welch, organization code 5810, (216) 433-8003.

12a. DISTRIBUTION/AVAILABILITY STATEMENT

12b. DISTRIBUTION CODE

Unclassified - Unlimited

Subject Category 07

This publication is available from the NASA Center for AeroSpace Information, (301) 621-0390.

13. ABSTRACT (Maximum 200 words)

The performance benefits derived by topping a gas turbine engine with a wave engine are assessed. The wave engine is a wave rotor that produces shaft power by exploiting gas dynamic energy exchange and flow turning. The wave engine is added to the baseline turboshaft engine while keeping high-pressure-turbine inlet conditions, compressor pressure ratio, engine mass flow rate, and cooling flow fractions fixed. Related work has focused on topping with pressure-exchangers (i.e., wave rotors that provide pressure gain with zero net shaft power output); however, more energy can be added to a wave-engine-topped cycle leading to greater engine specific-power-enhancement. The energy addition occurs at a lower pressure in the wave-engine-topped cycle; thus the specific-fuel-consumption-enhancement effected by ideal wave engine topping is slightly lower than that effected by ideal pressure-exchanger topping. At a component level, however, flow turning affords the wave engine a degree-of-freedom relative to the pressure-exchanger that enables a more efficient match with the baseline engine. In some cases, therefore, the SFC-enhancement by wave engine topping is greater than that by pressure-exchanger topping. An ideal wave-rotor-characteristic is used to identify key wave engine design parameters and to contrast the wave engine and pressure-exchanger topping approaches. An aerodynamic design procedure is described in which wave engine design-point performance levels are computed using a onedimensional wave rotor model. Wave engines using various wave cycles are considered including two-port cycles with on-rotor combustion (valved-combustors) and reverse-flow and through-flow four-port cycles with heat addition in conventional burners. A through-flow wave cycle design with symmetric blading is used to assess engine performance benefits. The wave-engine-topped turboshaft engine produces $16 \%$ more power than does a pressure-exchanger-topped engine under the specified topping constraints. Positive and negative aspects of wave engine topping in gas turbine engines are identified.

14. SUBJECT TERMS

Wave rotor; Wave engine; Gas turbine engine; Topping cycles 15. NUMBER OF PAGES 16 16. PRICE CODE $\mathrm{AO} 3$

\begin{tabular}{|c|c|c|}
\hline $\begin{array}{c}\text { 17. SECURITY CLASSIFICATION } \\
\text { OF REPORT } \\
\text { Unclassified }\end{array}$ & $\begin{array}{c}\text { 18. SECURTY CLASSIFICATION } \\
\text { OF THIS PAGE } \\
\text { Unclassified }\end{array}$ & $\begin{array}{c}\text { 19. SECURITY CLASSIFICATION } \\
\text { OF ABSTRACT } \\
\text { Unclassified }\end{array}$ \\
\hline
\end{tabular}

